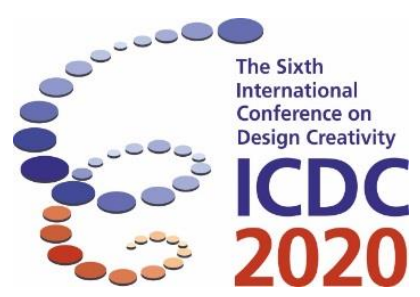

\title{
Forcing Creativity in Agile Innovation Processes through ASD-Innovation Coaching
}

\author{
Albert Albers ${ }^{1}$, Carsten Hahn ${ }^{2}$, Manuel Niever ${ }^{2}$, Jonas Heimicke ${ }^{1}$, \\ Florian Marthaler ${ }^{1}$ and Markus Spadinger ${ }^{1}$ \\ ${ }^{1}$ Institute of Product Engineering, Karlsruhe Institute of Technology, Karlsruhe, Germany \\ ${ }^{2}$ Faculty of Management Science and Engineering, University of Applied Sciences Karlsruhe, \\ Karlsruhe, Germany
}

\begin{abstract}
The challenge to handle uncertainties as well as a rapidly changing and challenging environment in product development is increasingly faced by implementing agile approaches and creativity methods into the companies' organization. To foster the goal of agility in product development processes the approach of Innovation Coaching in ASD - Agile Systems Design helps organizations to leverage their innovation potential. This empirical research defines the concept of ASD-Innovation Coaching, which enables product development teams to introduce and deepening their competencies into an agile and structured innovation process with the aim of implementing a degree of agility that is appropriate to the complexity of the task to be accomplished. The necessary activities of an ASDInnovation Coach are described and located contentwise in order to enable problem-solving teams in agile development projects of ASD. Coaching the team with a deep understanding of the technical system and agile approaches fosters systematic agility and generates increased creativity into development projects.
\end{abstract}

Keywords: ASD-Innovation Coaching, agile approaches, product development, coaching activities, ASD - Agile Systems Design

\section{Introduction}

In order to counter the technological and market-related uncertainties in the corporate environment and to uncover untapped potential, an agile product development process is required (Albers, Behrendt et al., 2017; Thomke \& Reinertsen, 1998). Due to the organizational requirements for agility in the innovation process, companies face great challenges in implementing these approaches (Dikert et al., 2016; Eppinger \& Chitkara, 2007; Schmidt et al., 2019). Supporting the removal of these challenges the involvement of interdisciplinary, partly external project participants in a joint development process offers many opportunities, but requires a clear distribution of tasks and a clear assignment of roles (Moran, 2015, pp. 12-16). The success of a development project depends on the actors and their individual characteristics. Consequently, innovation processes and methods should focus on people (Albers, Heimicke, Spadinger, Degner et al., 2019; Albers et al., 2013; Gericke et al., 2017). In order to ensure an agile and creative innovation process, actors must have freedoms, but also should be guided or moderated for a targeted and clearly structured approach (Albers, Heimicke, Spadinger, Degner et al., 2019). In order to 
take these aspects into account, there are various approaches to coaching development teams, which serve to increase performance (Berg \& Karlsen, 2007). However, there is no uniform definition or assignment of tasks for coaching (Stern, 2004). Coaching, like management in general, aims to make optimal use of the company's valuable existing resources and to develop the full potential of employees and optimize processes (Waldroop \& Butler, 1996). Although coaching is perceived as an important resource in companies, research into an actor who is firmly integrated into the development process and conducts clear interactions with the project team is not yet mature (Coutu \& Kauffman, 2009). With agile approaches such as SCRUM and Design Thinking, the role profiles of the Agile Coach, Scrum Master and the Design Thinking Coach have developed from practical experience. In our scientific research we are currently focusing on a concept of innovation coaching in which the central activities and responsibilities of an innovation coach are defined in order to enable agile innovation processes in the development of mechatronic systems (Hahn et al., 2017). Continuing, the aim of this paper is to define the innovation coaching concept within ASD to bring clear tasks and responsibilities in agile development processes in order to foster creativity and the innovation potential.

\section{Theoretical Framework}

\subsection{Innovation Processes as Problem Solving in Product Development Projects}

An innovation bases on a need situation, which is transferred into an idea which is implemented in a new form of a combination of technical solutions, services and business model and successfully introduced into the market (Albers, Heimicke et al., 2018). The resulting bundle of hybrid services (Gausemeier \& Plass, 2014, pp. 160), fulfils a certain value for a specific group of interested parties on the market (Anderson et al., 2006) and hereby leads to a success for the company through an introduction and the associated presence of the product on the market. (Albers, Heimicke et al., 2018) For the implementation of an innovation project the innovation process serves as an orientation and guideline. (Kaschny et al., 2015) This process is responsible for ensuring that market impulses are perceived and tracked, that customer's needs are always involved in the process, and that new trends and technologies are developed. (cf. Wördenweber, 2008, p. 1) This process can be understood as a problem-solving process (Albers, Reiß, Bursac, \& Breitschuh, 2016) in which an interdisciplinary team of developers transforms an undesired initial state into a desired final state, whereby the path to transfer is unknown (Dörner, 1979, p. 10). Since this is problem solving and not a reproducible procedure and the cognitive abilities of humans are limited (Dörner, 1979, 26ff.), problem solving methods can support this process. The number of problem-solving methods is large, but within this research we focus on the SPALTEN ${ }^{1}$ method according to Albers et al. (2005), since it is universally applicable - i.e. for solving technical as well as non-technical problems. Since different competencies are required within the seven phases of SPALTEN, the problem-solving team needs to be adjusted between each of them. (Albers, Reiß, Bursac, \& Breitschuh, 2016) The iPeM - integrated Product engineering Model takes up the problem-solving methodology SPALTEN and models the product engineering activities carried out by development teams within a product life cycle as a problem-solving process (Albers, Reiß, Bursac, \& Richter, 2016).

\subsection{ASD - Agile Systems Design}

In order to accelerate innovations in mechatronic systems development, the traditional innovation processes are replaced or supplemented with agile approaches in their sequential approach. There are various methods that can be applied in the context of agile product development such as SCRUM, Design Thinking, Lean start-up as well as scaled approaches like SAFe ${ }^{2}$. (Heimicke, Niever et al., 2019) In this respect, agile approaches are particularly suitable for projects that take place within an uncertain or complex environment (Snowden \& Boone, 2007) such as the further development of technologies or the opening up of new markets. However, in projects there always coexist problems with different degrees of complexity (Heimicke, Freire et al., 2019), whereby agile approaches for low-complexity problems

\footnotetext{
${ }^{1}$ SPALTEN is a German acronym for the seven steps of Situation Analysis, Problem Containment, Alternative Solutions, Selection of Solutions, Consequences Analysis, Make Decision, Recapitulate/Learn.

2 SAFe stands for „Scaled Agile Framework”
} 
are less suitable than plan-driven ones (Boehm \& Turner, 2003). In addition, products are developed in the sense of the model of the PGE - Product Generation Engineering in successive generations. These are developed on the basis of a reference system that includes existing references, such as (rejected) solutions from previous projects or (sub) systems implemented on the market by the company itself or another company. (Albers, Rapp et al., 2019) The requirements to agile approaches resulting from it are not covered by the existing agile approaches yet and as well, they lack the comprehensive integration of technical or process-related knowledge. (Heimicke, Niever et al., 2019)

The approach of ASD - Agile Systems Design is based on the Model of PGE and leads to a systematic combination of structuring and flexible elements in the product development process in order to support development teams in mechatronic system development according to the situation and demand. This occurs at different process levels depending on the degree of complexity present in each case. (Albers, Heimicke, Spadinger, Reiß et al., 2019) However, since each project is individual, the ASD - Agile Systems Design approach does not offer a methodical recipe for success in any development. Rather, the approach is based on nine basic principles, which represent guidelines for development teams in order to use a method constellation in process design that is tailored to the situation and requirements. These principles are (Albers, Heimicke, Spadinger, Reiß et al., 2019):

1. The developer is the centre of product development

2. Each product development process is unique and individual

3. Agile, situation- and demand-oriented combination of structuring and flexible elements

4. Each process element can be located in the system triple and each activity is based on the fundamental operators analysis and synthesis

5. All activities in product engineering are to be understood as a problem-solving process

6. Each product is developed on the basis of references

7. Product profiles, invention and business model form the necessary components of the innovation process

8. Early and continuous validation serves the purpose of continuous comparison between the problem and its solution

9. For a situation- and demand-oriented support in every development project, methods and processes must be scalable

These principles are used to generate individual process solutions (e.g. methods, communication models or process flows) with different weighting depending on the respective situation.

\subsection{Innovation Coaching}

The organizational culture is said to be of great importance for innovation performance in science as well as in practice. Various companies emphasize the high influence of the innovation culture as a driver for innovation. Considering the innovation culture and the corresponding development processes, dependencies can be identified. Surveys show, that the organizational culture issues are the biggest impediments to adopt and scale agile approaches in organizations. Furthermore, the respondent indicated that internal agile coaches are the most valuable in helping to scale agile practices followed by the executive sponsorship and company provided training programs. (VERSIONONE, 2019)

Considering the requirements of agile approaches, it is becoming increasingly important to have interdisciplinary and self-organizing teams in the early phases of innovation projects. Furthermore, to ensure that the innovation culture is lived in these teams and the overall organisation, a coach can be employed who deals with problem- and demand-oriented approaches as well as promotes team development and self-organized group work. This enables each individual team member to develop his or her skills. (O'Connell et al., 2014, p. 123) Within agile approaches, the role profiles of the Scrum Master, Design Thinking Coach or Agile Coach have developed from practical experience. Scientific research is currently focusing on a concept of Innovation Coaching, in which the central activities and responsibilities of an innovation coach are defined in order to facilitate agile innovation processes (Hahn et al., 2017). According to (Niever et al., 2019) "the concept of Innovation Coaching supports the human in agile innovation process within the model of PGE-Product Generation Engineering by the mediation of problem-solving skills, supporting the application to situation appropriate methods and the conscious management of the team development." Within empirical studies seven core competences were observed 
which are process-organization, communication skills, professional and methodical competence, teamwork, socio-emotional competence, innovation competence and leadership. (Niever et al., 2019) For the successful accomplishment of innovation projects based on or combined with agile approaches, the development teams can be supported process-oriented by a so-called Innovation Coach who additionally handle impediments, solves thinking barriers and promotes reflection and learnings. The Innovation Coach enhances the innovation capacity of the teams trough the combination of mediating and applying agile values and the integration of situationally appropriate development methods in innovation projects (Hahn et al., 2017).

\section{Need for Research}

Due to the fact that pure agile approaches are not always the right procedures in product development, but only at certain levels of maturity in certain projects, a combination of product-specific and processoriented approaches is in demand. The aim of the research is to expand the understanding of existing agile roles, such as the Agile Coach, Scrum Master and Design Thinking Coach, as well as the Innovation Coach, to include a technical focus and the Systems Engineering. The state of the art shows that the already good competencies of the agile roles in the application in mechanical engineering can be improved by integrating the technical understanding of product development. Therefore, this research aims at developing a coaching concept that enables product development teams to contribute their competencies to an agile and structured innovation process in order to implement a degree of agility that is appropriate to the complexity of the task to be accomplished. According to this objective, the following two research questions are answered in this article:

- How can the concept of innovation coaching be defined for use in agile development processes according to ASD - Agile Systems Design in order to include mindset, methods and processes of the model of PGE - Product Generation Engineering?

- Which activities does the Innovation Coach have to perform in order to enable problem-solving teams in agile development projects of ASD - Agile Systems Design to contribute their competencies in a targeted and effective way?

To answer these questions, the role profiles and frameworks of the existing coaching approaches were analysed and compared with the existing Innovation Coaching concept in the Live-Lab ProVIL-Product Development in a Virtual Idea Laboratory (Walter et al., 2016). This Live-Lab is a research environment based on an innovation project with 48 participants where master students in mechanical engineering develop products with an industry partner in a three-month period project work and get accompanied by industrial engineering students as Innovation Coaches (Albers, Walter et al., 2018). During the project work, qualitative and quantitative surveys as well as own observations are conducted regarding the key activities of the innovation coaches. With the findings of the ProVIL Live-Lab studies from 2017, 2018 and 2019, expert workshops with Coaches from practice and researchers were carried out to establish an initial definition for innovation coaching and to define the central activities and responsibilities.

\section{The Concept of ASD-Innovation Coaching}

As a result of the current research in the field of Innovation Coaching, an initial definition was created, which also describes the overarching goals and tasks of the Innovation Coach. The current description is based on comprehensive literature research, empirical studies in ProVIL and the practical experience from a panel of experts. Regarding the goal to enable development teams to integrate and deepening their competencies to an agile and structured innovation process, the Innovation Coaching concept bases on the ASD - Agile Systems Design approach, which offers a systematic combination of traditional and agile development. By integrating a broad technical understanding of product development, the concept is enhanced as ASD-Innovation Coaching.

Accordingly, ASD-Innovation Coaching is the process-oriented support of interdisciplinary teams in development projects, following the paradigm of Systems Engineering. It focuses on imparting problemsolving skills and consciously controlling team development. Within the organisation an innovation culture is to be developed, which has a corresponding influence on the work of the people in the development teams. During the project work, it is the task of the ASD-Innovation Coach to impart situationappropriate and human-centred methods to positively steer the team's creativity, technical work and 
team development. The method selection is made accordingly to the degree of maturity of problem and solution. In conclusion, the ASD-Innovation Coach understands the technical system and coaches the team for goal-oriented innovation by applying systematic agility. Based on the analysed understandings and the identified potentials the following definition of ASD-Innovation Coaching has been established:

ASD-Innovation Coaching is the process-oriented support of people in development projects by an organisation's internal coach, which follows the paradigm of systems engineering. The concept encourages the identification and promotion of all necessary competences for the actual development activities with the aim to set-up and realize self-organizing and cross-functional development teams. Core elements are the mediation of problem solving competencies, the ability to apply methods according to the situation and needs of the team as well as the conscious steering of the team development. By the target driven application of this elements a degree of agility is implemented that is appropriate to the complexity of the task to be accomplished.

This definition describes the concept of innovation coaching for applying agile development processes according to ASD - Agile Systems Design. It is particularly important at the beginning of the definition that the approach is human-centered. This means that on the one hand the people in the product development team are in focus and on the other hand they are supported by a human being, who acts as a coach for the team. Findings show that this human relationship can only be created by an internal coach and comes with the additional advantage that the corporate culture as well as technical and industryspecific knowledge are available. These prerequisites enable the coach to accompany the team in its work on innovations in a process-oriented as well as product-specific manner within the framework of ASD - Agile System Design.

The overall goal of ASD-Innovation Coaching is the (continued) development of an innovation culture within the organization. Due to importance regarding a change of the culture of the organization and its people by adapting agile approaches the ASD-Innovation Coach helps to understand and execute agility that is appropriate to the organization. This adoption is done by the process-oriented support of the selforganizing and cross-functional teams and its organizational environments. Integrating and enabling the right team competences in the development phases facilitates an effective and successful problem-solving team.

The ASD-Innovation Coach's task is to increase problem-solving skills during project work by imparting situational and human-centred methods to operationalise the ASD principles through early initiated measures and personal feedback. Thereby the independent solution development and the promotion of team self-reflection are of central importance. The situation- and demand-based application of methods of team coaching as well as product development help the team to work together effectively and to increase their ability to innovate.

\section{Understanding the Activities of the ASD-Innovation Coach}

The definition of ASD-Innovation Coaching involves individual and situation-related tasks and responsibilities, which should be brought together by a suitable coaching framework.

Empirical studies regarding the demand for process-oriented support of development teams in product development in combination with the Live-Lab Studies in ProVIL resulted in nine core activities an ASD-Innovation Coach should perform (see Figure 1). To model these activities the logic of the iPeM was used as a mental framework. This set of generic steps allows the uniform description, planning and execution of coaching activities in development projects. This helps the structuring and application of coaching activities towards the goal of ASD-Innovation Coaching. 


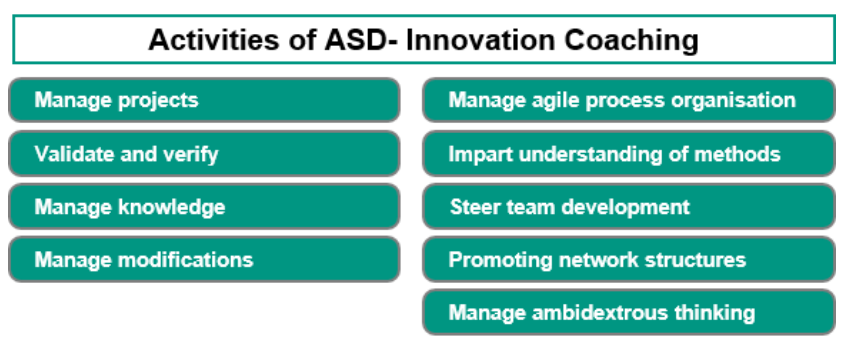

Figure 1: Basic and core activities of ASD-Innovation Coaching

The ASD-Innovation Coaching activities are divided into basic and core activities. The basic activities run parallel to all other activities with the aim to support, enhance and secure the coaching process within an innovation project. In contrast to the iPeM the activities refer to the team and its work instead of the product. The core activities are applied individually with regard to the situation and demand of the coached development team. All activities and resulting methods are structured based on the SPALTEN methodology. Explaining the activities shown in Figure 1 by using examples from previous development projects helps to assign to the ASD principles, which gives a deeper understanding of the integration of ASD-Innovation Coaching into the model of the PGE - Product Generation Engineering. Manage projects includes activities belonging to the team at the start of project such as setting up crossfunctional teams and sensitize the organizational environment for a self-organizing team. Concerning the team, an initial system of objectives (team-profile) and system of objects needs to be planed as well as continuously controlled. This suits to the ASD principle that each process element can be located in the system triple and each activity is based on the fundamental operators analysis and synthesis.

Validate and verify sum up the activities to continuously compare the systems of objects and objective, such as reviewing the team development concerning an open and effective communication. This early and continuous validation serves the purpose of continuous comparison between the problem and its solution.

Manage knowledge focuses on activities to support the identification, selection and development of the team's competences to facilitate an effective and successful problem-solving team. Next to set up a team with the needed competences these competences need to be controlled and adapted at each start of a new phase of the SPALTEN problem solving methodology and the associated development phases. As all activities in product engineering are to be understood as a problem-solving process these activities help to manage the knowledge of the team.

Manage modifications encompasses the coordination of changes regarding the team such as the team composition, social barriers, organizational environment. The elements are the detection of changes, assessment of their potential impacts to the team or the teams' work and the handling of the changes. As each product development process is unique and individual, the activity of managing changes is highly relevant.

These basic activities serve to support, enhance the development team within their innovation project. Parallel and iteratively run the core Activities of ASD-Innovation Coaching, which are applied individually with regard to the situation and demand of the team.

Manage agile process organisation contains methods to implement a degree of agility that is appropriate to the complexity of the task to be accomplished and the project the team works on. By understanding the challenges in Systems Engineering, the methods support the team to run through an agile and structured innovation process. Influencing the mindset and culture of the organization and its people will lead to goal-oriented innovation by applying systematic agility. This considers the principle of the agile, situation- and demand-oriented combination of structuring and flexible elements.

Impart understanding of methods focuses activities to help the team as well as the organizational environment to understand the relevance of applying methods and how to use them. Coaching toward the situation- and demand-based application of methods helps the team to increase their ability to innovate. For example the need for creativity methods will be explained first, then the right method will be selected with the team and continuative the application be moderated. For a situation- and demandoriented support in every development project, methods and processes must be scalable and therefore the teams need to be coached. 
Steer Team development includes all activities to support the human interaction within the team and the overall project. The developer is the center of product development and will be coached to unfold his skills and work effectively within his team.

Promoting network structures involves activities to foster networking and interacting with team members and stakeholders as knowledge carriers inside and outside the company. The enhancement of building and using a network considers the use of references by connecting the relevant knowledge carriers. These activities are based on the fact, that each product is developed on the basis of references.

Manage ambidextrous thinking sum up activities to enable the developer to simultaneously handle two action-oriented ways of thinking which are in a natural tension with each other: the exploitation of incremental improvements in structures and processes which feed the operating business and the exploration of new technologies and markets which bring uncertainty about the project's success. As Product profiles, invention and business model form the necessary components of the innovation process, the activities aim at coaching the team to handle the Ambidexterity of exploration and exploitation.

\section{Discussion and Conclusion}

Coaching agile development teams fosters creativity and agility in product development but needs to be adapted to the specificities of the system engineering. Due to the fact, that there is no clear definition and delimitation of existing roles in the area of innovation and agile coaching, the definition of ASDInnovation Coaching states the concept and explains how to implement it in agile development processes according to ASD - Agile Systems Design. This leads to a joint mindset, which brings clear tasks and responsibilities in complement to existing roles. To enable the problem-solving teams in innovation projects the activities of an ASD-Innovation Coach are described and integrated into the model of PGE - Product Generation Engineering. Both, the definition and the activities of ASD-Innovation Coaching result from the empirical research design within the projects of ProVIL and external interview partners who are experts in the area of innovation coaching. To further validate the generic activities the application of ASD-Innovation Coaching in practice is suitable. Based on the definition and core activities an ASD-Innovation Coaching framework should be developed. This will support the ASD-Innovation Coaches to execute the activities with existing and newly developed coaching methods.

Coaching development teams with a broad understanding of systems engineering and expertise in agile approaches fosters systematic agility and generates increased creativity into development projects. With the defined concept of ASD-Innovation Coaching and the associated activities, it is possible to implement a degree of agility that is appropriate to the complexity of the task to be accomplished.

\section{References}

Albers, A., Behrendt, M., Klingler, S., Reiß, N., \& Bursac, N. (2017). Agile product engineering through continuous validation in PGE - Product Generation Engineering. Design Science, 3, 16.

Albers, A., Burkhardt, N., Meboldt, M., \& Saak, M. (2005). Spalten Problem Solving Methodology in the Product Development. 15 International Conference on Engineering Design - ICED 2005.

Albers, A., Heimicke, J., Spadinger, M., Degner, N., \& Duehr, K. (2019). The Product Developer in the Centre of Product Development: A Systematic Literature Review on Describing Factors. Proceedings of the Design Society: International Conference on Engineering Design, 1(1), 1843-1852. https://doi.org/10.1017/dsi.2019.190

Albers, A., Heimicke, J., Spadinger, M., Reiss, N., Breitschuh, J., Richter, T., . . Marthaler, F. (2019). A systematic approach to situation-adequate mechatronic system development by ASD - Agile Systems Design. Procedia CIRP, 84, $1015-1022$. https://doi.org/10.1016/j.procir.2019.03.312

Albers, A., Heimicke, J., Walter, B., Basedow, G. N., Reiß, N., Heitger, N., . . Bursac, N. (2018). Product Profiles: Modelling customer benefits as a foundation to bring inventions to innovations. Procedia CIRP, 70(1), $253-258$. https://doi.org/10.1016/j.procir.2018.02.044

Albers, A., Maul, L., \& Bursac, N. (2013). Internal Innovation Communities from a User's Perspective: How to Foster Motivation for Participation. In M. Abramovici \& R. Stark (Eds.), Lecture Notes in Production Engineering. Smart Product Engineering (Vol. 44, pp. 525-534). Berlin, Heidelberg: Springer Berlin Heidelberg. https://doi.org/10.1007/978-3-642$\underline{30817-8 \quad 51}$

Albers, A., Rapp, S., Spadinger, M., Richter, T., Birk, C., Marthaler, F., . . Wessels, H. (2019). The Reference System in the Model of PGE: Proposing a Generalized Description of Reference Products and their Interrelations. Proceedings of the Design Society: International Conference on Engineering Design, 1(1), 1693-1702. https://doi.org/10.1017/dsi.2019.175 
Albers, A., Reiß, N., Bursac, N., \& Breitschuh, J. (2016). 15 Years of SPALTEN Problem Solving Methodology in Product Development. In C. Boks (Ed.), Proceedings of NordDesign 2016: August 10-12, 2016, Trondheim, Norway (pp. 411-420). Bristol, United Kingdom: The Design Society.

Albers, A., Reiss, N., Bursac, N., \& Richter, T. (2016). iPeM - Integrated Product Engineering Model in Context of Product Generation Engineering. Procedia CIRP, 50, 100-105. https://doi.org/10.1016/j.procir.2016.04.168

Albers, A., Walter, B., Wilmsen, M., \& Bursac, N. (2018). LIVE-LABS AS REAL-WORLD VALIDATION ENVIRONMENTS FOR DESIGN METHODS. In Design Conference Proceedings, Proceedings of the DESIGN $201815^{\text {th }}$ International Design Conference (pp. 13-24). https://doi.org/10.21278/idc.2018.0303

Anderson, J. C., Narus, J. A., \& van Rossum, W. (2006). Customer value propositions in business markets. Harvard Business Review, 84(3), 1-8.

Berg, M. E., \& Karlsen, J. T. (2007). Mental Models in Project Management Coaching. Engineering Management Journal, 19(3), 3-13. https://doi.org/10.1080/10429247.2007.11431736

Boehm, B., \& Turner, R. (2003). Using risk to balance agile and plan- driven methods. Computer, 36(6), 57-66. https://doi.org/10.1109/MC.2003.1204376

Coutu, D., \& Kauffman, C. (2009). What Can Coaches Do for You? Harvard Business Review, January 2009, 91-97. Retrieved from https://www.warriormindcoach.com/reports/HBR-What-Can-Coaches-Do-for-You.pdf

Dikert, K., Paasivaara, M., \& Lassenius, C. (2016). Challenges and success factors for large-scale agile transformations: A systematic literature review. Journal of Systems and Software, 119, 87-108. https://doi.org/10.1016/j.jss.2016.06.013

Dörner, D. (1979). Problemlösen als Informationsverarbeitung (2. Aufl.). Kohlhammer-Standards Psychologie Studientext. Stuttgart: Kohlhammer.

Eppinger, S., \& Chitkara, A. (2007). The new practice of global product development. IEEE Engineering Management Review, 35(1), 3. https://doi.org/10.1109/EMR.2007.329130

Gausemeier, J., \& Plass, C. (2014). Zukunftsorientierte Unternehmensgestaltung: Strategien, Geschäftsprozesse und ITSysteme für die Produktion von morgen (2., überarb. Aufl.). München: Hanser. https://doi.org/10.3139/9783446438422

Gericke, K., Eckert, C. M., \& Stacey, M. K. (2017). WHAT DO WE NEED TO SAY ABOUT A DESIGN METHOD? 21 ${ }^{S T}$ INTERNATIONAL CONFERENCE ON ENGINEERING DESIGN, ICED17.

Hahn, C., Albers, A., Stöckner, M., Niever, M., Walter, B., Kerres, R., \& Bursac, N. (2017). Innovation Coaching in Foresight Processes for Distributed Product Development. Proceedings of Collaborative European Research Conference CERC2017, 366-375.

Heimicke, J., Freire, G., Breitschuh, J., \& Albers, A. (2019). Determining degrees of complexity of different development situations within business processes in engineering sector. $41^{\text {st }} R \& D$ Management Conference 2019 "The Innovation Challenge: Bridging Research, Industry and Society".

Heimicke, J., Niever, M., Zimmermann, V., Klippert, M., Marthaler, F., \& Albers, A. (2019). Comparison of Existing Agile Approaches in the Context of Mechatronic System Development: Potentials and Limits in Implementation. Proceedings of the Design Society: International Conference on Engineering Design, 1(1), 2199-2208. https://doi.org/10.1017/dsi.2019.226

Kaschny, M., Nolden, M., \& Schreuder, S. (2015). Innovationsmanagement im Mittelstand: Strategien, Implementierung, Praxisbeispiele (Aufl. 2015). Wiesbaden: Springer Fachmedien Wiesbaden GmbH.

Moran, A. (2015). Managing Agile. Cham: Springer International Publishing. https://doi.org/10.1007/978-3-319-16262-1

Niever, M., Marthaler, F., Kosejian, M., Hahn, C., \& Albers, A. (2019). The Future of Innovation Coaching in Product Engineering: A Systematic Approach to Deriving the Future Competence Profile and its Development through Strategic Potential Identification. Proceedings of $5^{\text {th }}$ CERC 2019, 299-310.

O’Connell, B., Palmer, S., \& William, H. (2014). Lösungsorientiertes Coaching in der Praxis. Coaching skills kompakt: Vol. 2. Paderborn: Junfermann.

Schmidt, T. S., Atzberger, A., Gerling, C., Schrof, J., Weiss, S., \& Paetzold, K. (2019). Agile Development of Physical Products: An Empirical Study about Potentials, Transition and Applicability: Report, University of the German Federal Armed. Snowden, D. J., \& Boone, M. E. (2007). A Leader's Framework for Decision Making. Harvard Business Review, 85(11), 6877.

Stern, L. R. (2004). Executive coaching: A working definition. Consulting Psychology Journal: Practice and Research, 56(3), 154-162. https://doi.org/10.1037/1065-9293.56.3.154

Thomke, S., \& Reinertsen, D. (1998). Agile Product Development: Managing Development Flexibility in Uncertain Environments. California Management Review, 41(1), 8-30. https://doi.org/10.2307/41165973

VERSIONONE (2019). The $13^{\text {th }}$ annual State of Agile Report. Retrieved from https://www.stateofagile.com

Waldroop, J., \& Butler, T. (1996). The Executive as Coach. In Hooper (Hg.) 1996 - Leadership Perspectives (pp. 173-179). https://doi.org/10.4324/9781315250601-13

Walter, B., Albers, A., Haupt, F., \& Bursac, N. (2016). Produktentwicklung im virtuellen Ideenlabor - Konzipierung und Implementierung eines Live-Lab. 27. DfX-Symposium.

Wördenweber, B., Wickord, W., Eggert, M., \& Grösser, A. (2008). Technologie- und Innovationsmanagement im Unternehmen: Lean Innovation (3., neu bearbeitete und erw. Aufl.). Berlin: Springer. 